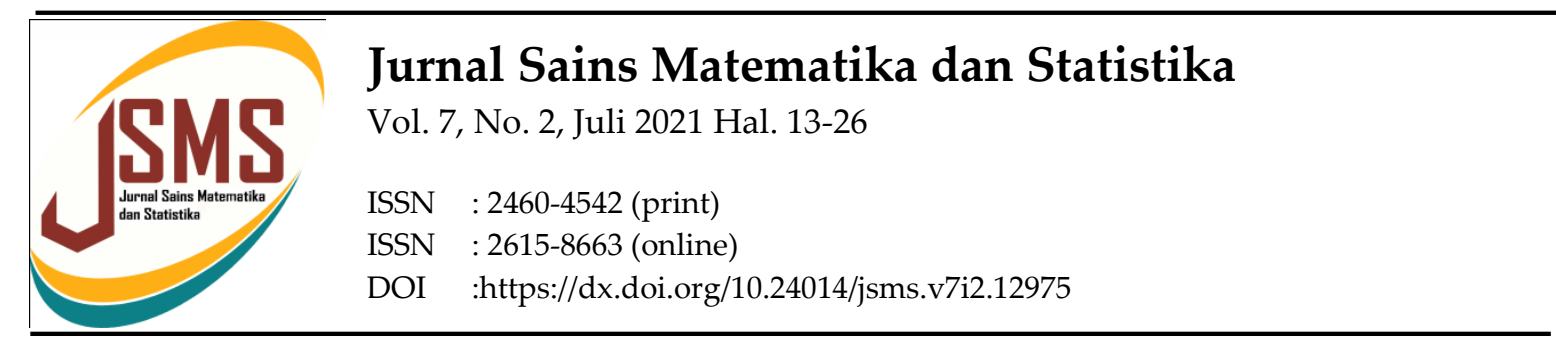

\title{
Analisis Pengendalian Persediaan Sepeda Motor Honda Dengan Penerapan Klasifikasi Always Better Control Pada Dealer Putra Suryajaya Raya II
}

\author{
Susi Susanti Komariah ${ }^{1}$, Riri Syafitri Lubis ${ }^{2 *}$, Hendra Cipta ${ }^{3}$ \\ 1,2 Prodi Matematika, Universitas Islam Negeri Sumatera Utara Medan \\ Jl. Lap Golf, Kp. Tengah, Kec. Pancur Batu, Kabupaten Deli Serdang, Sumatera Utara, 20353. \\ ${ }^{3}$ Prodi Matematika, Universitas Islam Negeri Sumatera Utara Medan \\ Jl. Lap Golf, Kp. Tengah, Kec. Pancur Batu, Kabupaten Deli Serdang, Sumatera Utara, 20353. \\ Email: ${ }^{1}$ susisusantimm@gmail.com. 2riri syafitri@uinsu.ac.id, ${ }^{3}$ hendracipta@uinsu.ac.id
}

\begin{abstract}
Abstrak
Dealer Putra Surya Jaya RayaII merupakan perusahaan yang menyediakan sepeda motor yang berkualitas dan bermutu baik. Sepeda motor merupakan transportasi yang dibutuhkan ditengah masyarakat sehingga memiliki permintaan peminat yang cukup meningkat, sehingga perusahaan harus memiliki pengendalian persediaan yang merupakan salah satu usaha yang dilakukan oleh perusahaan dalam penyediaan barang-barang yang dibutuhkan untuk proses produksi agar terpenuhi secara optimal sehingga proses produksi berjalan dengan lancar dan mengurangi dana resiko yang akan terjadi seperti kekurangan barang. Metode yang digunakan adalah klasifikasi ABC.Analisis $\mathrm{ABC}$ adalah metode pengklasifikasian barang berdasarkan peringkat nilai dari nilai tertinggi hingga terendah, dan dibagi menjadi 3 kelompok besar yang disebut kelompok A, B dan C. Dengan perhitungan safety stock maka pengendalian persedian sepeda motor akan menjadi optimal yaitu kelas A 6 merek sepeda motor lebih diperhatikan/prioritaskan. Berdasarkan perhitungan analisis $A B C$ yang digunakan untuk mengetahui prioritas sepeda motor yang termasuk kelompok A sebanyak 6 jenis atau 8,96\% dari seluruh jenis persediaan sepeda motor dengan nilai investasi sebesar Rp. 973.130 .000 atau $65,56 \%$ dari total investasi. Sepeda motor yang tergolong kelompok B sebanyak 5 jenis atau 7,46\% dari seluruh sepeda motor dengan nilai investasi sebesar Rp. 338.770 .000 atau $22,82 \%$ dari total investasisepeda motor. Sedangkan sepeda motor yang tergolong kelompok $C$ sebanyak 56 jenis atau $83,58 \%$ dari seluruh sepeda motor dengan nilai investasi sebesar Rp. 172.450 .000 atau 11,62\% dari total invetasi sepeda motor pada Dealer Resmi Honda Putra Surya Jaya Raya II Sosa.
\end{abstract}

Kata Kunci: Pengendalian, Persediaan, Sepeda Motor, Analisis, ABC.

Abstract 
Dealer Putra Surya Jaya Raya II is a company that provides quality and good quality motorcycles. Motorcycles are transportation that is needed in the community so that the demand for enthusiasts is quite increasing, so the company must have inventory control which is one of the efforts made by the company in providing the goods needed for the production process to be fulfilled optimally so that the production process runs smoothly. smoothly and reduce risk funds that will occur such as shortages of goods. The method used is the ABC classification. ABC analysis is a method of classifying goods based on value ratings from the highest to the lowest value, and is divided into 3 large groups called groups A, B and C. With the calculation of safety stock, motorcycle inventory control will be optimal, namely class A 6 motorcycle brands more attention/priority. Based on the calculation of the ABC analysis used to determine the priority of motorcycles included in group A as many as 6 types or $8.96 \%$ of all types of motorcycle inventory with an investment value of Rp. $973,130,000$ or $65.56 \%$ of the total investment. There are 5 types of motorcycles belonging to group B or $7.46 \%$ of all motorcycles with an investment value of Rp. $338,770,000$ or $22.82 \%$ of the total investment in motorcycles. While motorcycles belonging to group C as many as 56 types or $83.58 \%$ of all motorcycles with an investment value of Rp. 172,450,000 or $11.62 \%$ of the total investment in motorcycles at the Authorized Dealer Honda Putra Surya Jaya Raya II Sosa.

Keywords: Inventory, Control, Motorcycle, Analysis, ABC

Diterima : xx-xx-xxxx, Disetujui : xx-xx-xxxx, Terbit Online : xx-xx-xxxx

\section{Pendahuluan}

Pengendalian persediaan (stock control) adalah usaha yang dilakukan oleh perusahaan dalam penyediaan barang-barang yang dibutuhkan untuk proses produksi agar terpenuhi secara optimal sehingga proses produksi berjalan dengan lancar dan mengurangi dana resiko yang akan terjadi seperti kekurangan barang. Pengendalian persediaan harus dilakukan dengan seimbang [1]. Jika persediaan terlalu besar (over stock) maka beban-beban biaya untuk menyimpan dan menjaga persediaan di dalam gudang akan tinggi sehingga hal ini akan menyebabkan pemborosan. Sebaliknya, jika persediaan terlalu kecil atau dapat dikatakan kurangnya persediaan (out of stock) maka waktu pengiriman barang yang telah disepakati bersama antara perusahaan lain dalam melakukan pembelian barang [2].

Penyebab timbulnya persediaan ada tiga, yaitu mekanisme pemenuhan atas permintaan, keinginan untuk mengantisipasi ketidakpastian dan keinginan melakukan spekulasi sedangkan, metode perhitungan persediaan secara garis besar terdapat tiga metode, yaitu metode EOQ, metode ABC dan metode persediaan tunggal [3].

Penelitian ini di latar belakangi oleh masalah persediaan sepeda motor yang belum optimal. Jumlah Dealer di kabupaten Padang Lawas ini terdapat hanya 3 Dealer, dan Dealer Putra Surya Jaya resmi Honda merupakan salah satu Dealer Honda yang ada di padang lawas. Dealer Putra Surya Jaya Raya II harus mengelola persediaannya dengan baik sehingga memiliki ketersediaan dan kecukupan persediaan pada saat diperlukan oleh pengguna. Untuk dapat mengelola persediaan agar dapat memenuhi kebutuhan jumlah persediaan pada waktu yang tepat serta jumlah biaya yang rendah, maka 
diperlukan sistem pengendalian persediaan yang baik [4].Dealer Putra Surya Jaya Raya II perlu menerapkanmetode Klasifikasi Always Better Control untuk memudahkan pengendalian persediaan sepeda motor honda serta mengetahui klasifikasi berjenis apa saja yang lebih diminati masyarakat.

Adapun penelitian terdahulu yang telah berhasol menggunakan metode abc anatara lain sebagai berikut.Penerapan Metode ABC Terhadap Pengendalian Persediaan Bahan Baku Pada UD. Mayong Sari Probolinggo oleh [5]. Berdasarkan Hasil Penelitian Yang Telah Dilakukan Maka Dapat Disimpulkan Sebagai Berikut: 1. Berdasarkan Prinsip Klasifikasi Always Better ControlBahwa Tingkat Kepentingan Barang Dapat Ditinjau Dari Tigkat Kecepatan Pemakaian, Atau Tingkat Keuntungan Yang Dapat Diperoleh Dan Berdasarkan Tingkat Penyerapan Modal. Sehingga Bahan Baku Yang Masuk Kategori A Yaitu Paling Menyerap Dana Terbesar Adalah Tepung Dan Mentega. 2. Jenis Bahan Baku Dalam Membentuk Satu Unit Produk Roti Manis Ini Terdiri Dari 9 Jenis Komponen.Analisa Pengendalian Persediaan Gudang Barang Jadi Dengan Analisa ABC Pada Perusahaan Cat PT. PR. Dian F. 2019. Dari Hasil Uji Klasifikasi ABC Didapat 12 Produk Kelas A Yang Kemudian Diolah Menggunakan Metode Periodic Inventory System Dengan Simulasi Promodel. Penelitian Lain Yang Berkaitan Yaitu Oleh Pawitan, G. Dan Paramasatya, A. (2008) Dengan Judul Aplikasi Analisis Pareto Dalam Pengendalian Inventori Bahan Baku Pada Bisnis Restoran. Menggunakan Analisa Abc Dapat Dikelompokan Menjadi Tiga Kelompok, Yaitu Kelompok A Terdapat 16 Jenis Bahan Baku Dengan Nilai Penggunaan 83,08\%, Kelompok B Terdiri Dari 9 Jenis Bahan Baku Dengan Nilai Penggunaan 10,74 \% Dan Kelompok C Terdiri dari 9 Bahan Baku Dengan Nilai Penggunaan Sebesar 6,18\%.

Berdasarkan penelitian terdahulu diatas penulis menemukan masalah pada penelitian ini adalah Seperti apa pengendalian persedian sepeda motor pada Dealer Putra Surya Jaya Raya II dan sangat diperlukannya pengklasifikasian Sepeda Motor Honda pada Dealer Resmi Honda Putra Surya Jaya Raya II Ujung Batu Sosa dengan menggunakan metode ABC (Always Better Control) karena banyaknya permintaan masyarakat sehingga diperlukan metode yang terbaik dalam menyelesaikan masalah ini sehingga diketahui klasifikasi persedian yang optimal [6].

\section{Metode Penelitian}

Penelitian ini dilakukan di Dealer Honda Putra Surya Jaya Raya II Ujung Batu Sosa yang alamat Jl. Lintas Riau Kec. Sosa, Kabupaten Padang Lawas, Sumatera Utara. Waktu Penelitian ini dilakukan pada bulan April 2020 hingga bulan Maret 2021.

Studi pendahuluan dilakukan dengan melihat data yang ada, kondisi dilapangan dan melalukan wawancara dengan pihak perusahaan, dalam hal ini studi literatur dilakukan dengan mencari referensi sebagai bahan pendukung, kemudian merumuskan masalah. Setelah dilakukan rumusan masalah yang diperoleh adalah persedian sepeda motor pada Dealer Honda Putra Surya Jaya Raya II Ujung Batu Sosa yang mengalami ketidak optimalannya persedian karena nbanyaknya permintaan masyarakat.

\section{Landasan Teori}

\subsection{Persediaan}


Persediaan adalah kekayaan lancar yang terdapat dalam perusahaan dalam bentuk persediaan bahan mentah (bahan baku/raw material), barang setengah jadi (work in process), dan barang jadi ( finished goods) [5].

\subsection{Pengendalian persediaan}

Pengendalian persediaan merupakan kebijakan pengendalian untuk menentukan tingkat persediaan yang harus dijaga, kapan pesanan untuk menambah persediaan harus dilakukan dan berapa besar pesanan harus diadakan [7].

\subsection{Lead Time}

Lead time merupakan waktu yang diperlukan antara pemesanan dengan barang sampai di perusahaan sehingga lead time berhubungan dengan persedian barang digudangdan saat penerimaan barang.Lead time muncul karena setiap pesanan membutuhkan waktu dan tidak semua pesanan bisa dipenuhi seketika, sehingga selalu ada jeda waktu [8].

\subsection{Safety Stock}

Safety stock adalah persediaan tambahan yang diadakan untuk melindungi atau menjaga kemungkinan terjadi kekurangan bahan (stock out). Tujuan safety stock adalah untuk meminimalkan terjadinya stock out dan mengurangi penambahan biaya penyimpanan .Nilai dari safety stock dapat dihitung dengan menggunakan rumus.

$$
S S=\mathrm{Z} x \mathrm{~d} x L
$$

Dimana

Z : service level

d : pemakaian rata-rata

L : : lead time [9].

\subsection{Pengertian Metode ABC}

Analisis ABC adalah adalah metode pengklasifikasian barang berdasarkan peringkat nilai dari nilai tertinggi hingga terendah, dan dibagi menjadi 3 kelompok besar yang disebut kelompok A, B dan C [10].

\section{Hasil dan Pembahasan}

Jumlah Dealer di kabupaten Padang Lawas ini terdapat hanya 3 Dealer, dan Dealer Putra Surya Jaya resmi Honda merupakan salah satu Dealer Honda yang ada di padang lawas. Dealer Putra Surya Jaya resmi Honda adalah sebuah perusahaan yang bergerak dibidang manufaktur, distributor sepeda motor merek Honda.Setelah di evaluasi ternyata rata-rata permintaan sepeda motor meningkat setiap bulannya,karena banyaknya penjualan Sepeda Motor per bulannya, hal ini menyebabkan Dealer Putra Surya Jaya RayaII harus menyediakan sepeda motor yang cukup sesuai dengan kebutuhan agar mendukung pelayanan yang bermutudan dapat menambah nilai investasi bagi Dealer Putra Surya Jaya Raya II, Ujung Batu Sosa. Persedian sepeda motor honda ini sebaiknya disediakan oleh bagian pengandaan dan perusahaan karena jumlah permintaan tinggi sehingga 
jika stock persediaan kelompok ini tidak tersedia maka akan menyebabkan kerugian.

Berdasarkan telaah dokumen terdapat 67 jenis sepedamotor yang terdiri dari motor matichonda, motor cubhonda dan motor sport honda. Berikut merupakan sebagian data sepeda motor honda dengan jenis motor cub honda, motot matic honda dan motor sport honda.

Tabel 4.1

\section{Daftar Nama Sepeda Motor, Tipe, Jumlah Penjualan Perbulan, Jumlah Total Penjualan Perbulan Dan Harga Sepeda Motor}

\begin{tabular}{|c|c|c|c|c|c|c|}
\hline \multirow[t]{2}{*}{ No } & \multirow[t]{2}{*}{ Nama Sepeda Motor } & \multirow[t]{2}{*}{ Tipe } & \multicolumn{2}{|c|}{$\begin{array}{l}\text { Jumlah } \\
\text { Penjualan } \\
\text { Perbulan }\end{array}$} & \multirow[t]{2}{*}{$\begin{array}{l}\text { Total } \\
\text { Penjualan } \\
\text { Perbulan }\end{array}$} & \multirow[t]{2}{*}{$\begin{array}{l}\text { Harga } \\
\text { Sepeda } \\
\text { Motor }\end{array}$} \\
\hline & & & Juni & Juli & & \\
\hline 1 & ADV 150 abs & Matic & 0 & 0 & 0 & 38.370 .000 \\
\hline 2 & ADV $150 \mathrm{cbs}$ & Matic & 1 & 3 & 4 & 35.460 .000 \\
\hline 3 & All New Scoopy Stylish & Matic & 3 & 1 & 4 & 20.780 .000 \\
\hline 4 & All New Scoopy Sporty & Matic & 0 & 0 & 0 & 20.780 .000 \\
\hline 5 & CB 150R Streetfire & Sport & 4 & 0 & 4 & 28.310 .000 \\
\hline 6 & CB 150R Streetfire C & Sport & 0 & 2 & 2 & 29.410 .000 \\
\hline 7 & CB 150R Streetfire B & Sport & 1 & 1 & 2 & 29.410 .000 \\
\hline 8 & CB 150R Streetfire A & Sport & 0 & 0 & 0 & 29.410 .000 \\
\hline 9 & CBR 150R Abs (hm) & Sport & 0 & 0 & 0 & $40,840.000$ \\
\hline 10 & CBR 150R Abs (repsol) & Sport & 0 & 0 & 0 & 42.440 .000 \\
\hline 11 & CBR 150R Abs (mp) & Sport & 0 & 0 & 0 & 41.540 .000 \\
\hline 12 & CBR 150R Abs (hm matte) & Sport & 0 & 0 & 0 & 41.540 .000 \\
\hline 13 & CBR 150R Std (hm) & Sport & 0 & 0 & 0 & 36.840 .000 \\
\hline 14 & CBR 150R Std (bk matte) & Sport & 0 & 0 & 0 & 37.540 .000 \\
\hline 15 & CBR 150R Std (mp) & Sport & 0 & 0 & 0 & 38.240 .000 \\
\hline 16 & CBR 150R Std (hm matte) & Sport & 0 & 0 & 0 & 38.240 .000 \\
\hline 17 & CRF 150L (MP) & Sport & 0 & 0 & 0 & 35.430 .000 \\
\hline 18 & CRF 150L (BK) & Sport & 0 & 0 & 0 & 35.430 .000 \\
\hline 19 & CRF 150L (GR) & Sport & 0 & 0 & 0 & 35.430 .000 \\
\hline 20 & CRF $250 \mathrm{RL}$ & Sport & 0 & 0 & 0 & 83.390 .000 \\
\hline 21 & Forza & Matic & 0 & 0 & 0 & 81.770 .000 \\
\hline 22 & Genio 41L0 & Matic & 0 & 0 & 0 & 18.540 .000 \\
\hline 23 & Genio 42L0 & Matic & 0 & 0 & 0 & 19.020 .000 \\
\hline 24 & Genio 42L0A & Matic & 0 & 0 & 0 & 19.020 .000 \\
\hline 25 & Monkey 125 & Sport & 0 & 0 & 0 & 76.400 .000 \\
\hline 26 & New Beat F1 S CW & Matic & 0 & 0 & 0 & 17.340 .000 \\
\hline 27 & $\begin{array}{l}\text { New Beat Street F1 Pop } \\
\text { CW }\end{array}$ & Matic & 0 & 0 & 0 & 16.810 .000 \\
\hline 28 & New Beat Street F1 Pop & Matic & 0 & 0 & 0 & 17.010 .000 \\
\hline
\end{tabular}




\begin{tabular}{|c|c|c|c|c|c|c|}
\hline & CBS & & & & & \\
\hline 29 & $\begin{array}{l}\text { New Beat Street F1 Pop } \\
\text { CBS-ISS }\end{array}$ & Matic & 0 & 0 & 0 & 17.510 .000 \\
\hline 30 & New Beat Street & Matic & 4 & 7 & 11 & 18.180 .000 \\
\hline 31 & New Beat Sporty CBS & Matic & 3 & 6 & 9 & 18.440 .000 \\
\hline 32 & New Beat SportyCBS ISS & Matic & 5 & 4 & 9 & 18.150 .000 \\
\hline 33 & New Beat Sporty DX & Matic & 1 & 3 & 4 & 18.250 .000 \\
\hline 34 & New CBR 250 RR STD & Sport & 0 & 0 & 0 & 66.670 .000 \\
\hline 35 & New CBR 250 RR STD A & Sport & 0 & 0 & 0 & 61.850 .000 \\
\hline 36 & New CBR 250 RR STD B & Sport & 0 & 0 & 0 & 66.670 .000 \\
\hline 37 & New CBR 250 RR STD C & Sport & 0 & 0 & 0 & 67.270 .000 \\
\hline 38 & New CBR 250 RR ABS & Sport & 0 & 0 & 0 & 72.520 .000 \\
\hline 39 & New CBR 250 RR ABS A & Sport & 0 & 0 & 0 & 72.520 .000 \\
\hline 40 & New CBR 250 RR ABS B & Sport & 0 & 0 & 0 & 73.120 .000 \\
\hline 41 & New Revo Fit F1 & $\mathrm{Cub}$ & 7 & 5 & 12 & 15.730 .000 \\
\hline 42 & New Revo 110 CW F1 & $\mathrm{Cub}$ & 2 & 0 & 2 & 17.430 .000 \\
\hline 43 & $\begin{array}{l}\text { New Vario } 110 \text { ESP CBS } \\
\text { MMC }\end{array}$ & Matic & 0 & 0 & 0 & 18.270 .000 \\
\hline 44 & $\begin{array}{l}\text { New Vario } 110 \text { ESP CBS } \\
\text { Advanced MMC }\end{array}$ & Matic & 0 & 0 & 0 & 18.370 .000 \\
\hline 45 & $\begin{array}{l}\text { New Vario } 110 \text { ESP CBS } \\
\text { ISS MMC }\end{array}$ & Matic & 0 & 0 & 0 & 19.220 .000 \\
\hline 46 & $\begin{array}{l}\text { New Vario } 110 \text { ESP CBS } \\
\text { ISS Advanced MMC }\end{array}$ & Matic & 0 & 0 & 0 & 19.330 .000 \\
\hline 47 & $\begin{array}{l}\text { New Supra X125 Helm in } \\
\text { Injection }\end{array}$ & $\mathrm{Cub}$ & 0 & 1 & 1 & 19.890 .000 \\
\hline 48 & New Supra GTR 150 Sporty & $\mathrm{Cub}$ & 0 & 0 & 0 & 24.530 .000 \\
\hline 49 & $\begin{array}{l}\text { New Supra } \\
\text { Exclusive }\end{array}$ & $\mathrm{Cub}$ & 0 & 0 & 0 & 25.030 .000 \\
\hline 50 & New Cb 150 Verza CW & Sport & 2 & 1 & 3 & 21.670 .00 \\
\hline 51 & New Cb 150 Verza SW & Sport & 0 & 0 & 0 & 21.130 .000 \\
\hline 52 & Premium SH 150i DH & Matic & 0 & 0 & 0 & 41.930 .000 \\
\hline 53 & Premium SH 150i DK & Matic & 0 & 0 & 0 & 43.930 .000 \\
\hline 54 & PCX 150 CBS & Matic & 0 & 0 & 0 & 30.850 .000 \\
\hline 55 & PCX 150 ABS & Matic & 1 & 0 & 1 & 33.560 .000 \\
\hline 56 & PCX Hybrid & Matic & 0 & 0 & 0 & 43.110 .000 \\
\hline 57 & Sonic 150R & Sport & 0 & 0 & 0 & 24.120 .000 \\
\hline 58 & Sonic 150R HRR & Sport & 0 & 0 & 0 & 24.820 .000 \\
\hline 59 & Sonic 150R Matte Black & Sport & 0 & 0 & 0 & 24.820 .000 \\
\hline 60 & Super Cub C125 & $\mathrm{Cub}$ & 0 & 0 & 0 & 70.810 .000 \\
\hline 61 & Supra X125 SW MMC & $\mathrm{Cub}$ & 1 & 0 & 1 & 18.890 .000 \\
\hline 62 & Supra X125 CW MMC & $\mathrm{Cub}$ & 0 & 0 & 0 & 19.930 .000 \\
\hline 63 & Vario 125 & Matic & 0 & 0 & 0 & 24.740 .000 \\
\hline 64 & Vario $125 \mathrm{Cbs}$ & Matic & 0 & 0 & 0 & 21.390 .000 \\
\hline 65 & Vario 150 Iss & Matic & 1 & 0 & 1 & 22.140 .000 \\
\hline
\end{tabular}




\begin{tabular}{|l|l|l|l|l|l|l|}
\hline 66 & Vario 150 (bk) & Matic & 0 & 0 & 0 & 24.890 .000 \\
\hline 67 & Vario 150 (sporty) & Matic & 0 & 0 & 0 & 24.890 .000 \\
\hline
\end{tabular}

Formula Untuk mencari sebuah Nilai Investasi yaitu [11]:

$$
\text { Nilai investasi }=H \times J
$$

Dimana : H : Harga Sepeda Motor

$$
\mathrm{J} \text { : Jumlah sepeda motor }
$$

Dan Formula untuk mencari Persen Investasi (\%) yaitu:

$$
\text { Persen Investasi }(\%)=\frac{\text { Nilai investasi }}{\text { Jumlah Investasi }}
$$

Dari Formula diatas maka kita dapat menyelesaikan Nilai Investasi dan Persen Investasi untuk setiap jenis Sepeda Motornya. Berikut beberapa contoh langkah penyelesaiannya:

\section{ADV 150 abs}

Nilai investasi $=H \times J=R p .38 .370 .000 \times 0=R p .0$

Persen Investasi $(\%)=\frac{\text { Nilai investasi }}{\text { Jumlah Investasi }}=\frac{R p \cdot 0}{R p \cdot 1.484 .350 .000}=0 \%$

\section{ADV 150 cbs}

Nilai investasi $=H \times J=R p .35 .460 .000 \times 4=R p .141 .840 .000$

Persen Investasi $(\%)=\frac{\text { Nilai investasi }}{\text { Jumlah Investasi }}=\frac{R p \cdot 141 \cdot 840 \cdot 000}{R p \cdot 1 \cdot 484 \cdot 350 \cdot 000}=9,56 \%$

\section{All New Scoopy Stylish}

Nilai investasi $=H \times J=R p .20 .780 .000 \times 4=R p .83 .120 .000$

Persen Investasi $(\%)=\frac{\text { Nilai investasi }}{\text { Jumlah Investasi }}=\frac{R p \cdot 83 \cdot 120 \cdot 000}{R p \cdot 1.484 \cdot 350 \cdot 000}=5,60 \%$

\section{All New Scoopy Sport}

Nilai investasi $=H \times J=R p .20 .780 .000 \times 0=R p .0$

Persen Investasi (\%) $=\frac{\text { Nilai investasi }}{\text { Jumlah Investasi }}=\frac{R p .0}{R p \cdot 1.484 .350 .000}=0 \%$

\section{CB 150R Streetfire}


Nilai investasi $=H \times J=R p .28 .310 .000 \times 4=R p .113 .240 .000$

Persen Investasi (\%) $=\frac{\text { Nilai investasi }}{\text { Jumlah Investasi }}=\frac{R p \cdot 113 \cdot 240 \cdot 000}{R p \cdot 1 \cdot 484 \cdot 350 \cdot 000}=7,63 \%$

Dari penyelesaian diatas maka dapat kita gambarkan pada suatu tabel yaitu tabel Analisis Investasi/ Analisis Always Better Control sebagai berikut:

Tabel4.2

Tabel Kelompok Sepeda Motor Berdasarkan Analisis Investasi Periode Juni 2020-Juli 2020

\begin{tabular}{|c|c|c|c|c|c|c|c|c|}
\hline $\begin{array}{l}\mathrm{N} \\
\mathrm{O}\end{array}$ & Nama Sepeda Motor & Tipe & $\begin{array}{l}\text { Jumlah } \\
\text { penjuala } \\
\mathrm{n}\end{array}$ & $\begin{array}{l}\text { Harga Sepeda } \\
\text { Motor }\end{array}$ & Nilai Investasi & Presentase & $\begin{array}{l}\text { Presentase } \\
\text { Kumulatif }\end{array}$ & Kelompok \\
\hline 1 & New Beat Street & Matic & 11 & Rp 18.180 .000 & $\begin{array}{l}\text { Rp199.980.0 } \\
00\end{array}$ & 13,47 & 13,47 & $A$ \\
\hline 2 & New Revo Fit F1 & Cub & 12 & Rp 15.730.000 & $\begin{array}{l}\text { Rp188.760.0 } \\
00\end{array}$ & 12,72 & 26,19 & $A$ \\
\hline 3 & New Beat Sporty CBS & Matic & 9 & Rp 18.440 .000 & $\begin{array}{l}\mathrm{Rp} \\
165.960 .000\end{array}$ & 11,18 & 37,37 & $A$ \\
\hline 4 & $\begin{array}{l}\text { New Beat Sporty CBS } \\
\text { ISS }\end{array}$ & Matic & 9 & Rp 18.150 .000 & $\begin{array}{l}\text { Rp163.350.0 } \\
00\end{array}$ & 11,00 & 48.37 & $A$ \\
\hline 5 & ADV $150 \mathrm{cbs}$ & Matic & 4 & Rp35.460.000 & $\begin{array}{l}\text { Rp141.840.0 } \\
00\end{array}$ & 9,56 & 57,93 & $A$ \\
\hline 6 & CB 150R Streetfire & Sport & 4 & Rp $\quad 28.310 .000$ & $\begin{array}{l}\mathrm{Rp} \\
113.240 .000\end{array}$ & 7,63 & 65,56 & A \\
\hline 7 & All New Scoopy Stylish & Matic & 4 & Rp $\quad 20.780 .000$ & $\begin{array}{l}\mathrm{Rp} \\
83.120 .000\end{array}$ & 5,60 & 71,16 & B \\
\hline 8 & New Beat Sporty DX & Matic & 4 & Rp 18.250 .000 & $\begin{array}{l}\mathrm{Rp} \\
73.000 .000\end{array}$ & 4,92 & 76,08 & B \\
\hline 9 & New Cb 150 Verza CW & Sport & 3 & Rp 21.670 .000 & $\begin{array}{l}\mathrm{Rp} \\
65.010 . .000\end{array}$ & 4,38 & 80,46 & B \\
\hline 10 & CB 150R Streetfire C & Sport & 2 & Rp29.410.000 & $\begin{array}{l}\text { Rp58.820.00 } \\
0\end{array}$ & 3,96 & 84,42 & B \\
\hline 11 & & Sport & 2 & Rp 29.410.000 & $\mathrm{Rp}$ & 3,96 & 88,38 & B \\
\hline
\end{tabular}




\begin{tabular}{|c|c|c|c|c|c|c|c|c|}
\hline & CB 150R Streetfire B & & & & 58.820 .000 & & & \\
\hline 12 & PCX Hybrid & Matic & 1 & Rp 43.110 .000 & $\begin{array}{l}\text { Rp43.110.00 } \\
0\end{array}$ & 2,90 & 91,28 & C \\
\hline 13 & PCX 150 ABS & Matic & 1 & Rp 33.560 .000 & $\begin{array}{l}\text { Rp33.560.00 } \\
0\end{array}$ & 2,26 & 93,54 & C \\
\hline 14 & New Revo 110 CW F1 & Cub & 2 & Rp 17.430 .000 & $\begin{array}{l}\mathrm{Rp} \\
34.860 .000\end{array}$ & 2,35 & 95,89 & C \\
\hline 15 & Vario 150 Iss & Matic & 1 & Rp 22.140.000 & $\begin{array}{l}\mathrm{Rp} \\
22.140 .000\end{array}$ & 1,49 & 97,38 & C \\
\hline 16 & $\begin{array}{l}\text { New Supra X125 Helm } \\
\text { in Injectio }\end{array}$ & Botol & 1 & Rp19.890.000 & $\begin{array}{l}\text { Rp19.890.00 } \\
0\end{array}$ & 1,34 & 98,72 & C \\
\hline 17 & Supra X125 SW MMC & Cub & 1 & Rp18.890.000 & $\begin{array}{l}\text { Rp18.890.00 } \\
0\end{array}$ & 1,27 & 99,99 & C \\
\hline 18 & ADV 150 abs & Matic & 0 & Rp 38.370 .000 & $\mathrm{Rp}-$ & 0 & 99,99 & C \\
\hline 19 & All New scoopy sporty & Matic & 0 & Rp20.780.000 & $\mathrm{Rp}-$ & 0 & 99,99 & C \\
\hline 20 & CB 150R Streetfire A & Sport & 0 & Rp29.410.000 & $\mathrm{Rp}-$ & 0 & 99,99 & C \\
\hline 21 & CBR 150R Abs (hm) & Sport & 0 & Rp40.840.000 & $\mathrm{Rp}-$ & 0 & 99,99 & C \\
\hline 22 & CBR 150R Abs (repsol) & Sport & 0 & Rp42.440.000 & $\mathrm{Rp}$ & 0 & 99,99 & C \\
\hline 23 & CBR 150R Abs (mp) & Sport & 0 & $\mathrm{Rp} \quad 41.540 .000$ & $\mathrm{Rp}-$ & 0 & 99,99 & C \\
\hline 24 & $\begin{array}{l}\text { CBR 150R Abs (hm } \\
\text { matte) }\end{array}$ & Sport & & Rp41.540.000 & $\mathrm{Rp}-$ & 0 & 99,99 & C \\
\hline 25 & CBR 150R Std (hm) & Sport & 0 & Rp36.840.000 & $\mathrm{Rp}-$ & 0 & 99,99 & C \\
\hline 26 & $\begin{array}{lll}\begin{array}{l}\text { CBR } \\
\text { matte) }\end{array} & \text { Std } & \text { (bk } \\
\end{array}$ & Sport & 0 & Rp 37.540.000 & $\mathrm{Rp}-$ & 0 & 99,99 & C \\
\hline 27 & CBR 150R Std (mp) & Sport & 0 & Rp38.240.000 & $\mathrm{Rp}-$ & 0 & 99,99 & C \\
\hline 28 & $\begin{array}{llll}\begin{array}{l}\text { CBR } \\
\text { matte) }\end{array} & \text { Std } & \text { (hm } \\
\end{array}$ & Sport & 0 & Rp38.240.000 & $\mathrm{Rp}$ - & 0 & 99,99 & C \\
\hline 29 & CRF 150L (MP) & Sport & 0 & Rp35.430.000 & $\mathrm{Rp}-$ & 0 & 99,99 & C \\
\hline
\end{tabular}




\begin{tabular}{|c|c|c|c|c|c|c|c|c|c|}
\hline 30 & CRF 150L (BK) & Sport & 0 & Rp35.430.000 & $\mathrm{Rp}-$ & & 0 & 99,99 & C \\
\hline 31 & CRF $150 L$ (GR) & Sport & 0 & Rp35.430.000 & $\mathrm{Rp}-$ & & 0 & 99,99 & C \\
\hline 32 & CRF $250 \mathrm{RL}$ & Sport & 0 & Rp83.390.000 & $\mathrm{Rp}-$ & & 0 & 99,99 & C \\
\hline 33 & Forza & Matic & 0 & Rp 81.770 .000 & $\mathrm{Rp}-$ & & 0,06 & 99,99 & C \\
\hline 34 & Genio 41L0 & Matic & 0 & Rp18.540.000 & $\mathrm{Rp}-$ & & 0,05 & 99,99 & C \\
\hline 35 & Genio 42L0 & Matic & 0 & Rp 19.020.000 & $\mathrm{Rp}-$ & & 0,04 & 99.92 & C \\
\hline 36 & Genio 42LOA & Matic & 0 & Rp19.020.000 & $\mathrm{Rp}-$ & & 0,03 & 99.95 & C \\
\hline 37 & Monkey 125 & Sport & 0 & $\mathrm{Rp} 76.400 .000$ & $\mathrm{Rp}$ & & 0,02 & 99.97 & $\mathrm{C}$ \\
\hline 38 & New Beat F1 S CW & Matic & 0 & Rp 17.340.000 & $\mathrm{Rp}-$ & & 0,02 & 99.99 & C \\
\hline 39 & $\begin{array}{l}\text { GenNew Beat Street F1 } \\
\text { Pop CW }\end{array}$ & Matic & 0 & Rp 16.810 .000 & Rp- & & 0,01 & 99,99 & C \\
\hline 40 & $\begin{array}{l}\text { New Beat Street F1 } \\
\text { Pop CBS }\end{array}$ & Matic & 0 & Rp 17.010 .000 & $\mathrm{Rp}$ & & 0,01 & 99,99 & C \\
\hline 41 & $\begin{array}{l}\text { New Beat Street F1 } \\
\text { Pop CBS-ISS }\end{array}$ & Matic & 0 & Rp $\quad 17.510 .000$ & $\mathrm{Rp}$ & & 0 & 99,99 & c \\
\hline 42 & New CBR 250 RR STD & Sport & 0 & Rp 66.670 .000 & $\mathrm{Rp}$ & - & 0 & 99,99 & C \\
\hline 43 & New CBR 250 RR STD A & Sport & 0 & Rp 61.850 .000 & $\mathrm{Rp}$ & - & 0 & 99,99 & C \\
\hline 44 & New CBR 250 RR STD B & Sport & 0 & Rp66.670.000 & $\mathrm{Rp}$ & - & 0 & 99,99 & C \\
\hline 45 & New CBR 250 RR STD C & Sport & 0 & Rp 67.270 .000 & $\mathrm{Rp}$ & - & 0 & 99,99 & C \\
\hline 46 & New CBR 250 RR ABS & Sport & 0 & $\begin{array}{l}\mathrm{Rp} \\
72.520 .000\end{array}$ & $\mathrm{Rp}$ & - & 0 & 99,99 & C \\
\hline 47 & New CBR 250 RR ABS A & Sport & 0 & Rp72.520.000 & $\mathrm{Rp}$ & - & 0 & 99,99 & C \\
\hline 48 & New CBR 250 RR ABS B & Sport & 0 & $\mathrm{Rp} \quad 73.120 .000$ & $\mathrm{Rp}$ & - & 0 & 99,99 & C \\
\hline 49 & $\begin{array}{l}\text { New Vario } 110 \text { ESP CBS } \\
\text { MMC }\end{array}$ & Matic & 0 & Rp18.270.000 & $\mathrm{Rp}$ & - & 0 & 99,99 & c \\
\hline 50 & $\begin{array}{l}\text { New Vario } 110 \text { ESP CBS } \\
\text { Advanced MMC }\end{array}$ & Matic & 0 & Rp 18.370.000 & $\mathrm{Rp}$ & - & 0 & 99,99 & C \\
\hline
\end{tabular}




\begin{tabular}{|c|c|c|c|c|c|c|c|c|c|}
\hline 51 & $\begin{array}{l}\text { New Vario } 110 \text { ESP CBS } \\
\text { ISS MMC }\end{array}$ & Matic & 0 & Rp19.220.000 & $\mathrm{Rp}$ & - & 0 & 99,99 & C \\
\hline 52 & $\begin{array}{l}\text { New Vario } 110 \text { ESP CBS } \\
\text { ISS Advanced MMC }\end{array}$ & Matic & 0 & Rp19.330.000 & $\mathrm{Rp}$ & - & 0 & 99,99 & C \\
\hline 53 & $\begin{array}{l}\text { New Supra GTR } 150 \\
\text { Sporty }\end{array}$ & Cub & 0 & Rp 24.530.000 & $\mathrm{Rp}$ & - & 0 & 99,99 & C \\
\hline 54 & $\begin{array}{l}\text { New Supra GTR } 150 \\
\text { Exclusive }\end{array}$ & Cub & 0 & Rp25.030.000 & $\mathrm{Rp}$ & & 0 & 99,99 & C \\
\hline 55 & New Cb 150 Verza SW & Sport & 0 & Rp 21.130.000 & $\mathrm{Rp}$ & & 0 & 99,99 & C \\
\hline 56 & Premium SH 150i DH & Matic & 0 & Rp41.930.000 & $\mathrm{Rp}$ & - & 0 & 99,99 & C \\
\hline 57 & Premium SH 150i DK & Matic & 0 & Rp43.930.000 & $\mathrm{Rp}$ & - & 0 & 99,99 & C \\
\hline 58 & PCX 150 CBS & Matic & 0 & Rp30.850.000 & $\mathrm{Rp}$ & _ & 0 & 99,99 & C \\
\hline 59 & PCX Hybrid & Matic & 0 & Rp43.110.000 & $\mathrm{Rp}$ & - & 0 & 99,99 & C \\
\hline 59 & Sonic 150R & Sport & 0 & Rp24.120.000 & $\mathrm{Rp}$ & - & 0 & 99,99 & C \\
\hline 60 & Sonic $150 R$ HRR & Sport & 0 & Rp24.820.000 & $\mathrm{Rp}$ & - & 0 & 99,99 & C \\
\hline 61 & Sonic 150R Matte Black & Sport & 0 & Rp24.820.000 & $\mathrm{Rp}$ & - & 0 & 99,99 & C \\
\hline 62 & Super Cub C125 & Cub & 0 & Rp70.810.000 & $\mathrm{Rp}$ & - & 0 & 99,99 & C \\
\hline 63 & Supra X125 CW MMC & Cub & 0 & Rp19.930.000 & $\mathrm{Rp}$ & - & 0 & 99,99 & C \\
\hline 64 & Vario 125 & Matic & 0 & Rp24.740.000 & $\mathrm{Rp}$ & - & 0 & 99,99 & C \\
\hline 65 & Vario $125 \mathrm{Cbs}$ & Matic & 0 & Rp21.390.000 & $\mathrm{Rp}$ & - & 0 & 99,99 & C \\
\hline 66 & Vario 150 (bk) & Matic & 0 & Rp24.890.000 & $\mathrm{Rp}$ & - & 0 & 99,99 & C \\
\hline 67 & Vario 150 (sporty) & Matic & 0 & Rp24.890.000 & $\mathrm{Rp}$ & - & 0 & 99,99 & C \\
\hline
\end{tabular}


Hasil analisis Always Better Control Sepeda Motor Honda berdasarkan nilai investasi dapat di klasifikasikan berdasarkan Kelompok A,B dan C pada priode Juni 2020- Juli 2020 sebagai berikut:

TABEL 3

Analis ABC Sepeda Motor Honda berdasarkan investasiPeriode Juni - Juli 2020

\begin{tabular}{|c|c|c|c|c|}
\hline $\begin{array}{l}\text { Kelompok } \\
\text { Sepeda } \\
\text { Motor }\end{array}$ & $\begin{array}{l}\text { Jumlah } \\
\text { Penjualan } \\
\text { Sepeda } \\
\text { Motor }\end{array}$ & $\begin{array}{l}\text { Presentase } \\
\text { Jumlah jenis } \\
\text { Sepeda } \\
\text { Motor(\%) }\end{array}$ & Nilai Investasi Juni & $\begin{array}{l}\text { Presentase } \\
\text { Nilai } \\
\text { Investasi (\%) }\end{array}$ \\
\hline A & 6 & 8,96 & Rp. $\quad 973.130 .000$ & 65,56 \\
\hline B & 5 & 7,46 & Rp. $\quad 338.770 .000$ & 22,82 \\
\hline $\mathrm{C}$ & 56 & 83,58 & $\begin{array}{ll}\text { Rp. } & 172.450 .000\end{array}$ & 11,62 \\
\hline Total & 67 & 100 & Rp. $\quad 1.484 .350 .00$ & 100 \\
\hline
\end{tabular}

Sumber : Hasil Pengolahan Data Sekunder

\section{Persediaan Pengaman (Safety Stock)}

Dalam hal ini, faktor pengaman yang dimaksudkan adalah besar probabilitas yang digunakan perusahaan terhadap terjadinyapersedian kosong. perusahaan menggunakan probabilitas sebesar 5\% terjadinya stockout, maka dengan menggunakan tabel distribusi frekuensi normal didapat nilai $Z=0.05=1,65$ [12]. Misalnya untuk:

1. New Beat Street:

$(d)=0,18$

$$
Z=1,65
$$

$(S S)=2$

2. New Revo Fit F1:

$(d)=0,2$

$\mathrm{Z}=1,65$

$(S S)=2$

Tabel 3

Jumlah Safety Stock Untuk Masing-Masing Sepeda Motor Kelompok A

\begin{tabular}{|l|l|l|l|l|l|}
\hline No. & \multicolumn{1}{|c|}{ Nama Sepeda Motor } & $\begin{array}{l}\text { Jumlah } \\
\text { Pemakain }\end{array}$ & $\begin{array}{l}\text { Jumlah } \\
\text { Pemakaian } \\
\text { Perhari }\end{array}$ & $\mathrm{Z}=1,6$ & $\begin{array}{l}\text { SS } \\
\text { ( unit) }\end{array}$ \\
\hline 1 & New Beat Street & 11 & 0,18 & 1,65 & 2 \\
\hline 2 & New Revo Fit F1 & 12 & 0,2 & 1,65 & 2 \\
\hline 3 & New Beat Sporty CBS & 9 & 0,15 & 1,65 & 2 \\
\hline 4 & New Beat Sporty CBS ISS & 9 & 0,15 & 1,65 & 2 \\
\hline
\end{tabular}




\begin{tabular}{|l|l|l|l|l|l|}
\hline 5 & ADV 150 cbs & 4 & 0,06 & 1,65 & 1 \\
\hline 6 & All New Scoopy Stylish & 4 & 0,06 & 1,65 & 1 \\
\hline
\end{tabular}

\section{Kesimpulan dan Saran}

Berdasarkan perhitungan analisis $\mathrm{ABC}$ yang digunakan untuk mengetahui prioritas sepeda motor yang termasuk kelompok A sebanyak 6 jenis atau $8,96 \%$ dari seluruh jenis persediaan sepeda motor dengan nilai investasi sebesar Rp. 973.130 .000 atau 65,56\% dari total investasi. Sepeda motor yang tergolong kelompok B sebanyak 5 jenis atau 7,46\% dari seluruh sepeda motor dengan nilai investasi sebesar Rp. 338.770 .000 atau 22,82\% dari total investasisepeda motor. Sedangkan sepeda motor yang tergolong kelompok C sebanyak 56 jenis atau 83,58\% dari seluruh sepeda motor dengan nilai investasi sebesar Rp. 172.450 .000 atau 11,62\% dari total invetasi sepeda motor pada Dealer Resmi Honda Putra Surya Jaya Raya II Sosa.Dengan demikian perusahaan dapat mengoptimalkan persedian sepeda motor pada DealerHonda Putra Surya Jaya Raya II Sosa.

\section{Daftar Pustaka}

[1] A. Wibisono, "Penerapan Analisis ABC Dalam Pengendalian Persediaan Produk Furniture Pada Java Furniture," vol. 53, no. 9, pp. 1689-1699, 2009.

[2] Hawari Adelia, Istianah Muslim, and Yuli Fitrisia, "Sitem Informasi Penjualan dan Pengendalian Persediaan Dengan Klasifikasi ABC Pada Toko XYZ," Semin. Nas. Teknol. Inf. Komun. dan Ind., vol. 0, no. 0, pp. 276-281, 2018, [Online]. Available: http://ejournal.uinsuska.ac.id/index.php/SNTIKI/article/view/6079.

[3] I. Chatisa, I. Muslim, and R. P. Sari, "Implementasi Metode Klasifikasi ABC pada Warehouse Management System PT. Cakrawala Tunggal Sejahtera," J. Nas. Tek. Elektro dan Teknol. Inf., vol. 8, no. 2, 2019, doi: 10.22146/jnteti.v8i2.501.

[4] T. Wahyuni, "Penggunaan Analisis Abc Untuk Pengendalian Persediaan Barang Habis Pakai : Studi Kasus Di Program Vokasi Ui," J. Vokasi Indones., vol. 3, no. 2, 2016, doi: 10.7454/jvi.v3i2.30.

[5] Junaidi, "Penerapan Metode ABC Terhadap Pengendalian Persediaan Bahan Baku Pada UD.Mayong Sari Probolinggo," vol. 2, pp. 161-164, 2019.

[6] I. Farida and M. N. Rozini, "Pengendalian Persediaan Spare Part Dan Pengembangan Dengan Konsep 80-20 ( Analisis Abc ) Pada Gudang Suku Cadang Pt . Astra International Tbk - Daihatsu," Semin. Nas. IPTEK Terap. ISBN 978-602-74355-0-6, vol. 20, pp. 163-169, 2016. 
[7] A. Meilani, "Pengendalian Persediaan Spare Part Dan Pengembangan Dengan Konsep 80-20 (Analisis ABC) Pada AUTO2000 Cabang Sutoyo Malang," e-conversion - Propos. a Clust. Excell., vol. 20, 2018.

[8] A. Handiyoko, “Universitas Sumatera Utara 7,” pp. 7-37, 2015.

[9] A. Serawasti, S. Wahyudi, D. Surjanto, J. Matematika, F. Matematika, and P. Alam, "Klasifikasi ABC dengan multi-kriteria menggunakan Ng-Model untuk pengendalian persediaan," J. Sains dan Seni Pomits, vol. 3, no. 2, 2014.

[10] S. Farhah, "Penerapan Metode ABC untuk Penentuan Harga Pokok Produksi pada CV. Rumah Kerudung Jihan," vol. 87, no. 1,2, pp. 149-200, 2017.

[11] B. Wiyono, "Artikel Skripsi Universitas Nusantara PGRI Kediri ANALISIS PENERAPAN METODE," Ekon. Akunt., vol. 01, no. 08, pp. 1-13, 2014.

[12] Q. Ikhwanina, "Analisis Penentu Re-Order Point (Rop) Kedelai Untuk Kelancaran Proses Produksi Tempe Pada Raja Tempe Di Nganjuk Tahun 2015," Simki-Economic, vol. 01, no. 04, 2017. 